Supplement of Biogeosciences, 13, 5205-5219, 2016

http://www.biogeosciences.net/13/5205/2016/

doi:10.5194/bg-13-5205-2016-supplement

(C) Author(s) 2016. CC Attribution 3.0 License.

(c) (i)

Supplement of

\title{
Phytoplankton community structure in the VAHINE mesocosm experiment
}

\section{Karine Leblanc et al.}

Correspondence to: Karine Leblanc (karine.leblanc@univ-amu.fr)

The copyright of individual parts of the supplement might differ from the CC-BY 3.0 licence. 

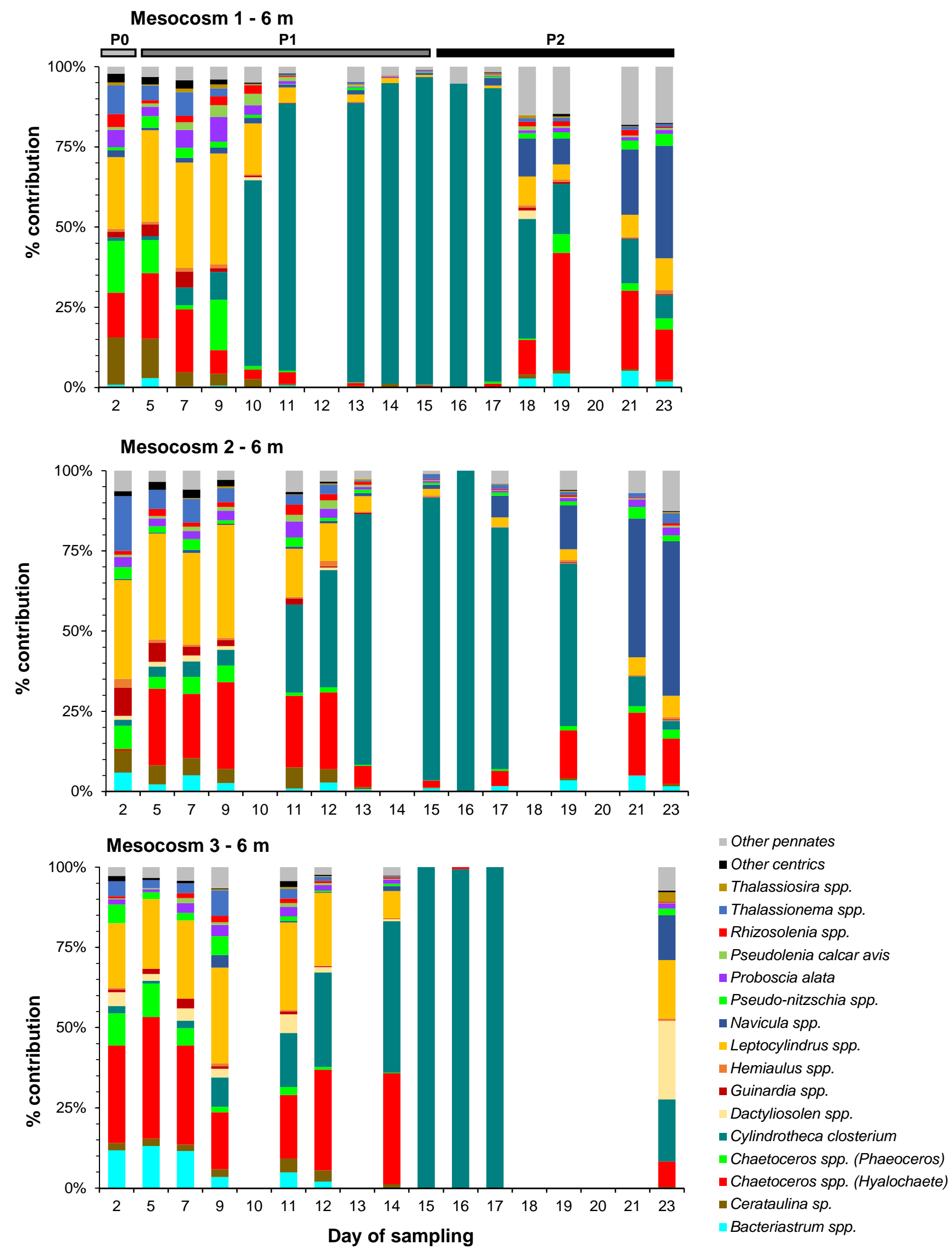

Figure S1: Main diatom genera/species composition in \% contribution at the intermediate depth (6 $\mathrm{m})$ in each mesocosm. 


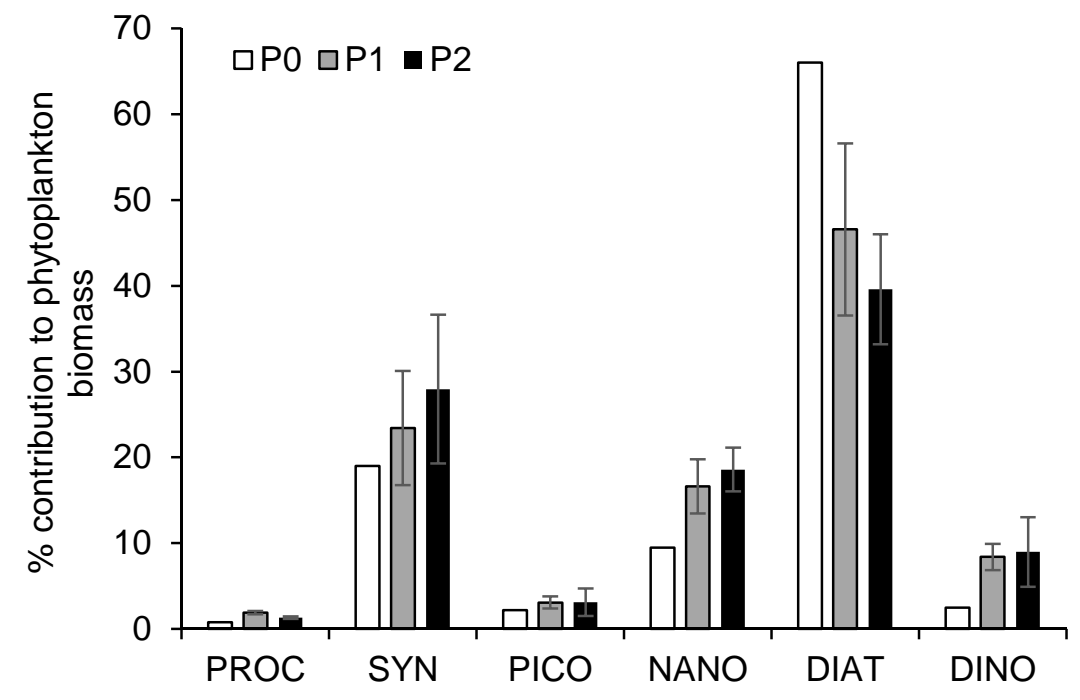

Figure $S 2$ : Average ( $\pm S D$ ) contribution to $C$ biomass of the main groups constituting phytoplankton communities (diazotrophs not included) over the course of the experiment following the three periods $\mathrm{PO}$, P1 and P2 for Prochlorococcus (PROC), Synechococcus (SYN), pico-phytoeukaryotes (PICO), nanophytoeukaryotes (NANO), diatoms (DIAT) and dinoflagellates (DINO). 